\title{
Opiate Influences on Nucleus Accumbens Neuronal Electrophysiology: Dopamine and Non-Dopamine Mechanisms
}

\author{
R. L. Hakan and S. J. Henriksen \\ Department of Neuropharmacology, Research Institute of the Scripps Clinic, La Jolla, California 92037
}

\begin{abstract}
Single-unit recordings of nucleus accumbens septi (NAS) neurons in halothane-anesthetized rats revealed that microinfusions of morphine into the ventral tegmental area (VTA) primarily inhibited spontaneously active NAS units. These inhibitory effects were reversed by alpha-flupenthixol (s.c.), suggesting a role for dopamine (DA) in the observed opiateinduced effect. VTA opiate microinfusions also inhibited the evoked (driven) responses of silent cells (spontaneously inactive) in the NAS elicited by stimulation of hippocampal afferents to the NAS. In addition, this inhibition of driven response was reversed by naloxone (s.c.) but not by alphaflupenthixol, implying a VTA-mediated non-DA mechanism. Morphine applied iontophoretically to cells within the NAS inhibited spontaneous activity but not fimbria-driven cellular activity, suggesting that the systemic effects of opiates on NAS activity can be mediated directly in the NAS as well as through VTA afferents. Moreover, since VTA-induced inhibition of fimbria-driven activity was reversed by systemic opiates, opiates also can exert effects through other, as yet unidentified NAS afferent systems.
\end{abstract}

The nucleus accumbens septi (NAS) is a basal forebrain structure that can be distinguished in part from adjacent brain regions (e.g., the caudate nucleus) by its differential patterns of neural connectivity (Heimer and Wilson, 1975; Swanson and Cowan, 1975; Powell and Leman, 1976; Williams et al., 1977; Nauta et al., 1978; Troiano and Siegel, 1978; Groenwegen et al., 1980; Newman and Winans, 1980; Chronister and De France, 1981; Kelley and Domesick, 1982; Kelley and Stinus, 1984; Phillipson and Griffiths, 1985). The NAS receives substantial input from limbic structures (e.g., hippocampus, amygdala, septal nuclei, cingulate cortex, mammillary bodies) and projects to nuclei mediating extrapyramidal motor functions (the ventral pallidal region). Thus, some researchers have suggested the NAS serves to integrate motivation-related inputs that are vital to goalseeking behaviors (Beninger, 1983; Mogenson, 1987). Moreover, the NAS also seems critical for the locomotor stimulant effects elicited by many drugs of abuse (Pigenberg and Van Rossum, 1973; Kelly et al., 1975; Jones and Mogenson, 1980; Wise, 1984; Swerdlow et al., 1986; Ksir and Kline, 1987; Mogenson, 1987). For example, animal studies suggest that the NAS is critical for supporting the self-administration of drugs having

\footnotetext{
Received Feb. 10, 1989; accepted Mar. 9, 1989.

This research was supported by PHS grants DA03665 and AA06420 (Johnson and Johnson Publication BCR5515).

Correspondence should be addressed to Dr. Steven Henriksen, Research Institute of the Scripps Clinic,BCR-1, 10666 N. Torrey Pines Rd., La Jolla, CA 92037. Copyright (C) 1989 Society for Neuroscience $0270-6474 / 89 / 103538-09 \$ 02.00 / 0$
}

abuse potential for humans such as the opiate alkaloids (Goeders et al., 1984; Vaccarino et al., 1985; Corrigal and Vaccarino, 1988; Koob and Goeders, 1989). Although there is controversy regarding the precise neuropharmacological mechanism(s) underlying opiate actions on the NAS and on NAS-related brain circuitry (e.g., see Wise, 1987), behavioral research has indicated that these drugs may exert pharmacological influence over NAS function via dopamine (DA)-dependent and DA-independent projections from the DA containing cell bodies of the midbrain ventral tegmental area (VTA) (Bozarth and Wise, 1981), the cellular origin of the DA-ergic input to the NAS (see Kelly et al., 1980; Stinus et al., 1980; Kalivas et al., 1983; Pettit et al., 1984; Amalric and Koob, 1985; Vaccarino et al., 1986; Wise, 1987; Di Chiara and Imperato, 1988; Koob and Goeders, 1989).

Electrophysiological studies have shown that morphine will excite VTA-DA projection neurons when administered either systemically (Nowycky et al., 1978; Glysing and Wang, 1983) or electrophoretically onto identified VTA-DA neurons (Hu and Wang, 1984; Mathews and German, 1984). Moreover, excitation of NAS activity by hippocampal or amygdala stimulation is inhibited by VTA conditioning stimulation, and this effect is mimicked by the actions of iontophoretically applied dopamine in the NAS (Yim and Mogenson, 1982; Yang and Mogenson, 1984; but see Akaike et al., 1981). Finally, opioid receptors primarily of the $\mu$-receptor subtype exist in the NAS (Wamsley et al., 1980; Herkenham et al., 1984; Unterwald et al., 1986), providing a substrate for direct action of opioids on NAS neurons.

Recently, the electrophysiological effects of systemically administered opiates on NAS single-units have been described (Hakan and Henriksen, 1987). While systemically administered opiate alkaloids inhibited the majority of single-cells recorded (55\%), significant numbers of other NAS cells were either excited $(19 \%)$ or unaffected $(25 \%)$. It is possible that the heterogeneity of NAS responses to systemically administered opiates is a consequence of combined direct opiate effects in the NAS as well as indirect opiate effects mediated by NAS afferents such as the mesolimbic DA projections originating from the VTA. The present experiments were designed to assess electrophysiologically the roles of DA-dependent and DA-independent processes underlying opiate actions on NAS neurons.

\section{Materials and Methods}

Male Sprague-Dawley rats weighing 250-350 gm were used in these experiments. Subjects were housed 3 per cage and allowed free access to food and water. The animal housing facility was maintained at a constant temperature $\left(21-23^{\circ} \mathrm{C}\right)$ and normal lighting cycle. The subjects were tested during the light phase.

Individual rats were prepared for acute electrophysiological recordings in the following manner: Subjects were first anesthetized with $2 \%$ 
halothane in air; a tracheotomy was performed, and the rats were then placed in a stereotaxic holder (Kopf). Body temperature was monitored by rectal probe and maintained at $36^{\circ} \mathrm{C}$ by a thermostatically controlled abdominal heating pad. Light anesthesia was maintained with $0.6-0.8 \%$ halothane in air delivered to the subject through the implanted tracheal tube. A craniotomy was performed to allow insertion of a bipolar concentric stimulating electrode (Rhodes Medical, SNE-100) in the fimbria (A $2.0 \mathrm{~mm}$, L $2.0 \mathrm{~mm}$ from bregma and DV -4.0 to $-5.0 \mathrm{~mm}$ from brain surface; Paxinos and Watson, 1982) and to allow placement of a single or a multibarrel glass micropipette used for recording unit activity and "population" field responses evoked by fimbria stimulation. Singlebarrel micropipettes (9-50 M $\Omega$ resistance) or one of the barrels of the multibarrel micropipettes (10-25 M $\Omega$ ) were backfilled with Pontamine sky blue (PSB) in $0.5 \mathrm{M}$ sodium acetate and lowered with a microdrive unit (Narishige) into the NAS (A +1.1 to $2.2 \mathrm{~mm}, \mathrm{~L}-1.1$ to $-1.7 \mathrm{~mm}$ from bregma, and DV -5.7 to $-7.3 \mathrm{~mm}$ from brain surface) ipsilateral to the stimulating electrode. A 23 gauge cannula (10 mm long) prefit with a 30 gauge stylet to prevent plugging of the tip was inserted 1.5 $\mathrm{mm}$ above the ipsilateral VTA (A $-5.0 \mathrm{~mm}, \mathrm{~L}-0.8 \mathrm{~mm}$ from bregma and DV $-6.5 \mathrm{~mm}$ from brain surface). Both stimulating electrode and recording electrode coordinates were adjusted as necessary to maximize NAS field responses to fimbria stimulation (De France and Yoshihara, 1975; Hakan and Henriksen, 1987) as well as to discriminate singleunit activity.

Single square-wave monophasic current pulses $(0.15 \mathrm{msec}$ duration and approximately $100-600 \mu \mathrm{A}$ intensity) were delivered to the ipsilateral fimbria at $0.1 \mathrm{~Hz}$ by a stimulus generator (Grass S-88) coupled to an optically isolated stimulus isolation unit. Amplified electrical signals from the recording electrode were either unfiltered (for field potential recording) or filtered (1-20 kHz for single-unit activity) and displayed on oscilloscopes. Randomly encountered single-unit potentials were separated from background noise by a voltage-gated window discriminator (Neurolog systems), and the discriminated output was relayed to a chart recorder (Gould) and to a computer (MINC, digital Equipment) for spike-train analysis. Systemically administered naloxone $(4.0 \mathrm{mg} / \mathrm{kg})$, alpha-flupenthixol $(0.5 \mathrm{mg} / \mathrm{kg})$, or heroin $(0.5 \mathrm{mg} / \mathrm{kg})$ were administered in a volume of $1 \mathrm{mg} / \mathrm{ml}$ through a subcutaneous injection needle inserted into the flank region. Prior to isolation of NAS single-unit activity, the cannula stylet was replaced by a 30 gauge injection needle $(11.0 \mathrm{~mm}$ in length) connected to PE-10 tubing so that morphine $(2.5 \mu \mathrm{g}$ in $1 \mu \mathrm{l})$ could be later infused (over $1 \mathrm{~min}$ ) to the VTA with the aid of a $5.0 \mu \mathrm{l}$ Hamilton syringe and syringe pump. The injection needle then remained in the cannula for the remainder of the experimental session. All drug doses used in these studies were chosen on the basis of studies indicating behavioral or biochemical effectiveness (e.g., Kalivas et al., 1983; Vaccarino et al., 1985, see Koob and Goeders, 1989). Standard 4-barrell micropipettes (Omega Dot, $0.25 \mathrm{~mm} \mathrm{o.d.)}$ with tip diameters ranging from 5-8 $\mu \mathrm{m}$ were used for iontophoresis. The PSB-filled barrel was used for recording. Two barrels were filled with morphine sulfate $(0.2 \mathrm{M}, \mathrm{pH} 4.5)$ or naloxone $(0.01 \mathrm{M}, \mathrm{pH} 4.0)$. The fourth barrel was filled with $\mathrm{NaCl}(3.0 \mathrm{~m})$ for automatic current balancing. Negative current $(-5$ to $-15 \mathrm{nA})$ was used to prevent passive diffusion of substances from the pipette tips. Morphine and naloxone were ejected with positive current $(+5$ to $+30 \mathrm{nA})$ by an iontophoresis unit (Neurophore-BH-2). Onset and offset of ionotophoretic ejection currents were monitored on the chart recorder.

In all experiments, single units were isolated and determined to be stable (defined as a constant pattern of activity for at least $10 \mathrm{~min}$ ), and baseline interspike interval histograms and peristimulus histograms were compiled via the on-line computer (ISH, PISH, K. Liebold, DECUS Library, Digital, Marlboro, MA) before drugs were applied. In cases where evoked single units (driven cells) were tested, quantified records of baseline occurrences were visually counted and recorded both at suband supermaximal stimulation current values. Postdrug signal analysis was then conducted for at least $\mathbf{4 0}$ min following systemic administrations, at least $5 \mathrm{~min}$ after initiation of iontophoretic ejection current or until drug effects were evident. Except for experiments that employed microiontophoresis, only one unit was examined in this fashion per subject. Alpha-flupenthixol and/or naloxone (or heroin; see below) were administered approximately 10 min after onset of morphine effects when attempting to reverse these effects. ANOVAs were used to assess the significance of observed effects, and opiate effects were considered valid only if a reversal was subsequently observed. In a subset of control experiments, VTA saline microinfusions were administered and NAS cell activity was monitored as described above. Electrode and cannulae
TABLE 1. THE EFFECTS OF FIMBRIA STIMULATION ON NAS SINGLE UNIT ACTIVITY

\begin{tabular}{|c|c|c|}
\hline \multicolumn{3}{|c|}{ TOTAL \# OF NAS CELLS RECORDED - 372} \\
\hline \multicolumn{3}{|c|}{ TOTAL \# OF (QUIET) DRIVEN CELLS -118 (32\%) } \\
\hline \multicolumn{2}{|c|}{ TOTAL \# OF SLOW CELLS } & $-149(40 \%)$ \\
\hline \multicolumn{2}{|c|}{ TOTAL \# OF FAST CELLS } & $-105(28 \%)$ \\
\hline \multicolumn{3}{|c|}{$\begin{array}{l}\text { EFFECTS OF STIMULATION ON } \\
\text { SPONTANEOUSLY ACTIVE NAS CELLS }\end{array}$} \\
\hline & N CELLS & FAST CELLS \\
\hline EXCITED & 22 & 15 \\
\hline INHIBITED & 31 & 25 \\
\hline $\begin{array}{l}\text { DRIVEN } \\
\text { (w/spont.) }\end{array}$ & 56 & 18 \\
\hline COMPLEX & 20 & 29 \\
\hline NO EFFECT & 20 & 18 \\
\hline
\end{tabular}

\section{AVERAGE LATENCIES OF ALL DRIVEN CELLS}

$5-12 \mathrm{~ms} \quad 13-25 \mathrm{~ms}$ BOTH OTHER

\begin{tabular}{l}
$70 \quad 66$ \\
\hline
\end{tabular}

The data reflect the single-cell electrophysiological profile of the NAS region and the variety of effects fimbria stimulation exerts on NAS cellular activity. Fimbria stimulation-evoked cellular responses from quiet cells (driven), slow ( $<4 \mathrm{~Hz}$ ) and fast $(>4 \mathrm{~Hz}$ ) NAS cellular activity were encountered throughout the NAS with essentially equal probability (see text for further details). Fimbria stimulation would typically drive NAS silent cells (but also some spontaneously active cells) at 7 or $17 \mathrm{msec}$, though other patterns of response were sometimes seen (see Fig. 2). Fimbria stimulation also had a variety of effects on spontaneously active NAS units (see Fig. 2). In addition to pure excitation or inhibition, these responses were sometimes complex in that combinations of excitations, inhibition, and drive werc clicited.

sites were later identified using the following verification procedure: At the end of each recording session, PSB was injected from the recording electrode by electrophoresis $(10-15 \mathrm{~min}$ at $10 \mu \mathrm{A}) ; 0.5 \mu 1$ PSB was also infused through the VTA cannula to mark its location, and lesions were made by positive current $(500 \mu \mathrm{A}, 10 \mathrm{sec})$ through the stimulating electrodes. The subjects were then killed by anesthestic overdose, and their brains were removed and stored in formalin. Identification of the electrode lesion sites was accomplished by saturation of the formalin with potassium ferricyanide. A blue spot was observed in histological sections where the potassium ferricyanide had reacted with the ferrous residues deposited at the electrode-lesion sites.

\section{Results}

Spontaneous cellular activity and fimbria driven activity in the NAS and adjacent regions

A total of 372 histologically identified cells were recorded in the NAS. Although the majority of these cells were recorded in the posteromedial portion of the NAS $(n=197)$, where cellular activity was encountered most frequently, many cells were also recorded throughout the greater NAS region $(n=175)$. In general, slow $(<4 \mathrm{~Hz})$ bursty cells, fast-firing cells, and silent (driven) cells were encountered equally throughout the NAS. Moreover, for all cells encountered there was similar diversity of 
FIELD \& CELL 327

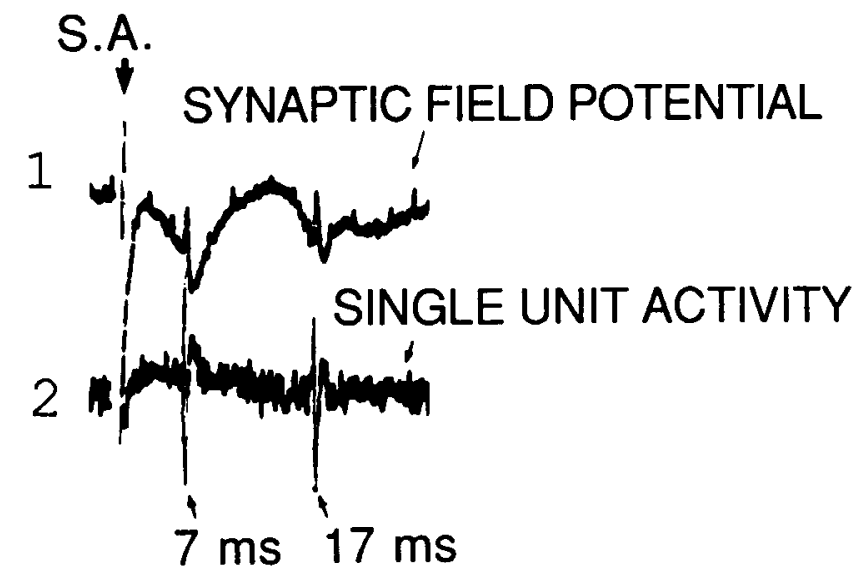

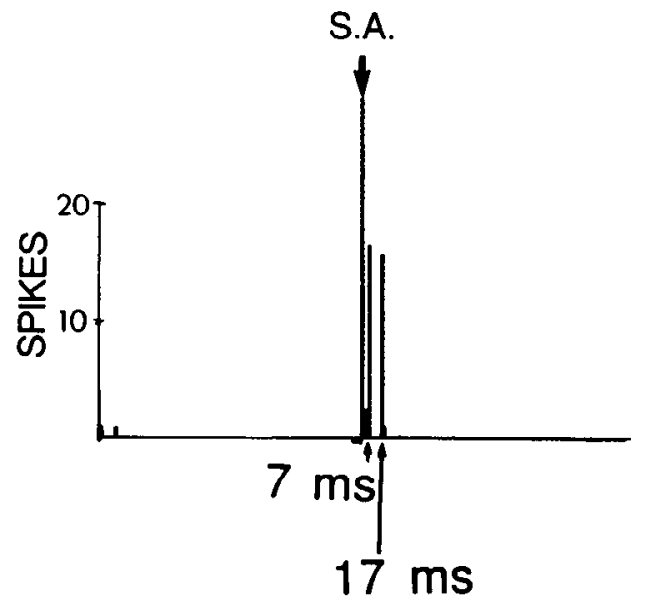

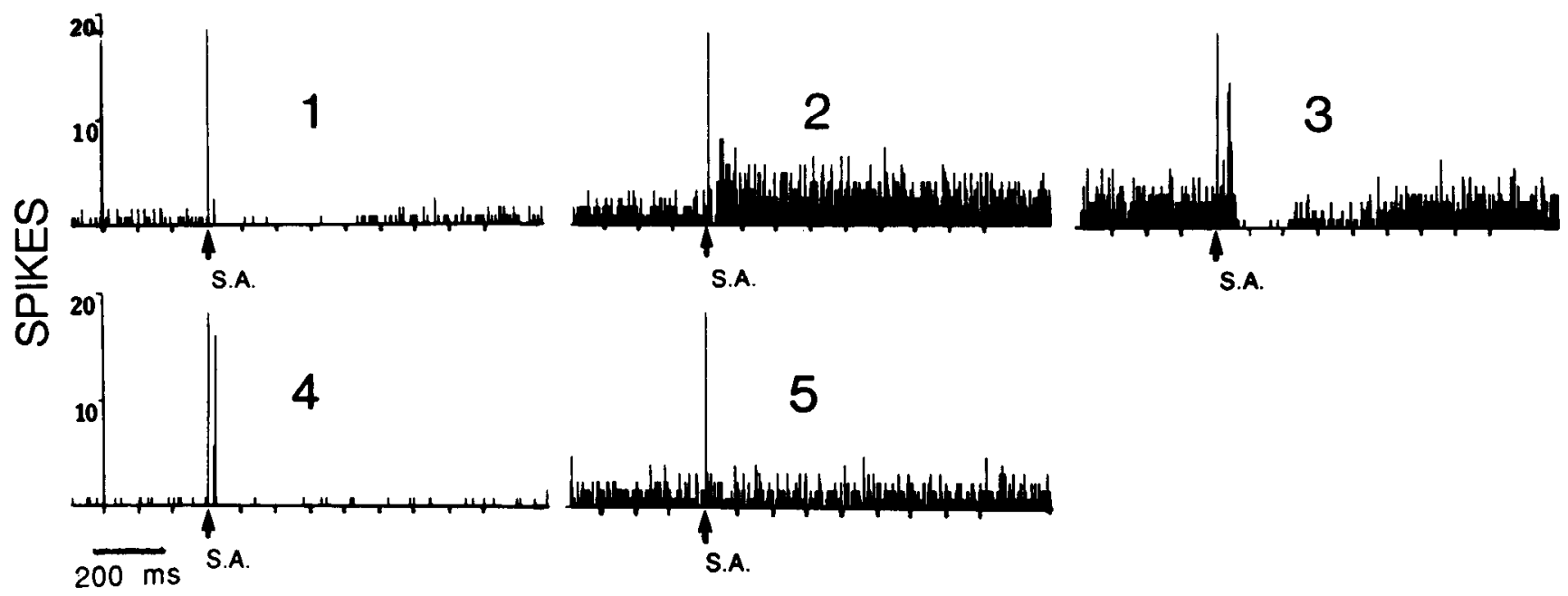

Figure 1. Fimbria stimulation-evoked "field" responses and neuronal activity in the NAS. A: 1, Representative fimbria-evoked population field potential in the NAS. Two components to this field were typically observed: an early negative deflection with a peak latency of approximately 7 msec and a later negative deflection with a peak latency of approximately $17 \mathrm{msec}$. 2, Evoked cellular activity from neurons that were otherwise inactive. These "driven cells" had characteristic latencies that usually coincided with the field component peaks at 7 and 17 msec. The most common response of this type consisted of single discharges at either 7 or 17 msec. Less frequently, discharges would be seen simultaneously at both 7 and $17 \mathrm{msec}$ and on more rare occasions other discharge patterns would occur. $B$, Computer-generated peristimulation rate histogram (PISH; stimulation $=500 \mu \mathrm{A}$ at $0.1 \mathrm{~Hz}$ for 25 sweeps) for the fimbria-driven cell shown in $A$. These histograms aided in the quantification of cell discharge rates and response to stimulation. $C$, Similarly generated PISHs for spontaneously active NAS units representative of the different responses to fimbria stimulation observed in the NAS: 1 , inhibition; 2 , excitation; 3, drive/inhibition; 4, drive with a low rate of associated spontaneous activity; 5 , no effect (see text for further description of NAS cellular responsiveness to fimbria stimulation). S.A., stimulation artifact.

cellular characteristics when examined on the basis of rate of discharge, burstiness, patterns of discharge, extracellularly recorded waveforms, or response to fimbria stimulation. An exception to this heterogeneity was observed at the ventral NAS and olfactory tubercle border, where fast-firing units $(>4 \mathrm{~Hz}$; mean, $10 \mathrm{~Hz}$ ) were encountered with more regularity than were slow or driven cell types.

\section{Effects of fimbria stimulation on NAS activity}

Fimbria stimulation evoked several types of responses from the NAS region. A population "field" response was consistently evoked with 2 negative deflections occurring at approximately 7 and 17 msec poststimulation (see Fig. 2, $A-1$ ). This field was consistently observed though the amplitude of the field deflec- 

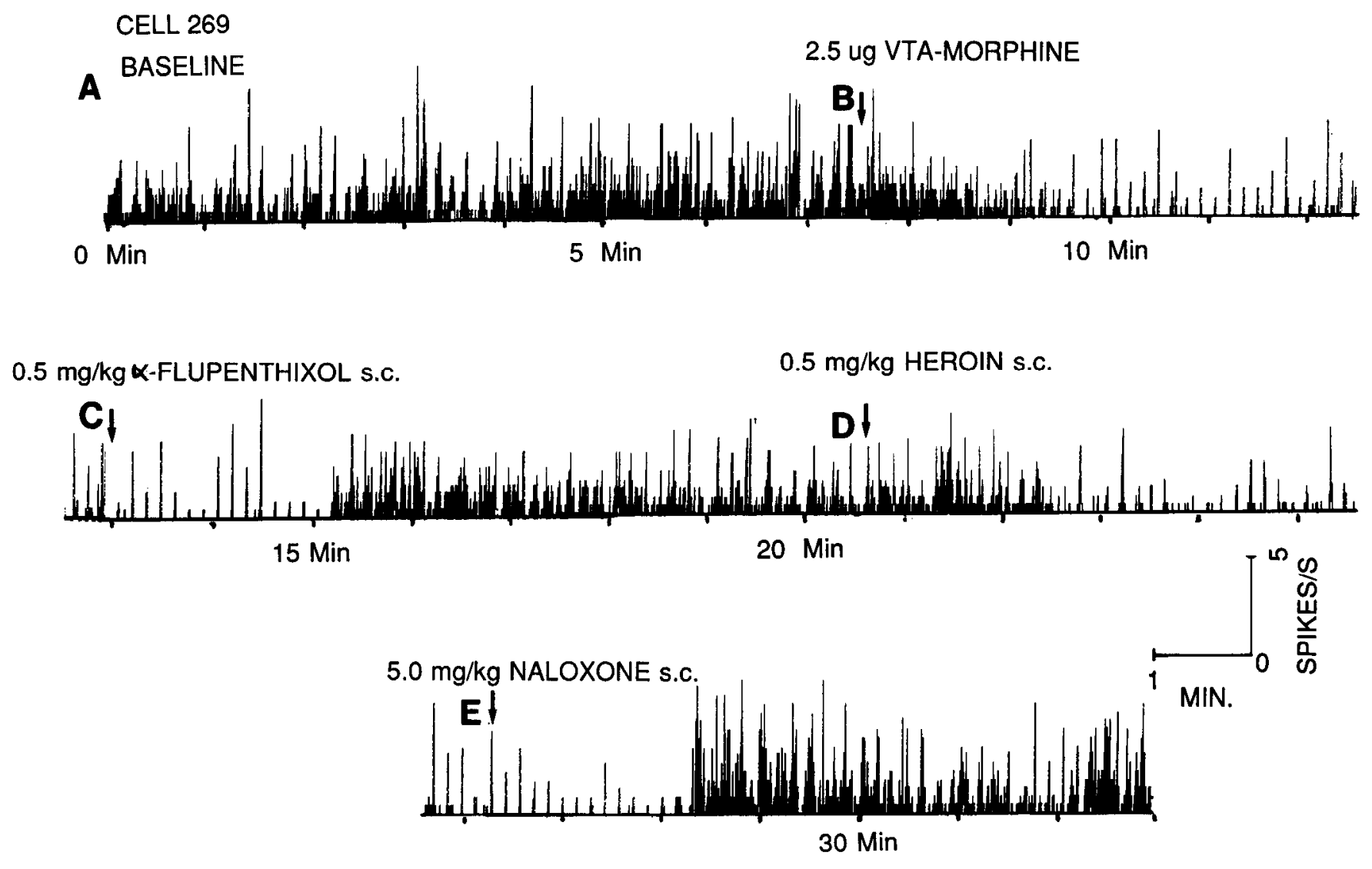

Figure 2. Dopamine-dependent and dopamine-independent effects of morphine on the NAS. The ratemeter records shown above were collected from a spontaneously active $(\approx 3 \mathrm{~Hz})$ NAS cell which was stimulated at $0.1 \mathrm{~Hz}$ by an electrode located in the ipsilateral fimbria. $A$, Baseline rate of spontaneous activity for this cell. $B$, Inhibitory effect of VTA-morphine microinfusion (administration indicated by arrow) on cell discharge rate. The onset of this inhibition was observed at approximately $2 \mathrm{~min}$ postinfusion and was observed for approximately 5 min before alphaflupenthixol was administered $(0.5 \mathrm{mg} / \mathrm{kg}$, s.c.). The subsequent reversal of this inhibition by alpha-flupenthixol $(C)$ was seen at approximately 3 min postinjection. $D$, The same spontaneously active cell is inhibited by heroin $(0.5 \mathrm{mg} / \mathrm{kg}$, s.c.) while alpha-flupenthixol is still present in the system (alpha-flupenthixol $+10 \mathrm{~min})$. $E$, The heroin-induced inhibition is reversed by naloxone $(4.0 \mathrm{mg} / \mathrm{kg}, s . c$.).

tions rarely exceeded $2 \mathrm{mV}$. Action potentials of silent cells were sometimes evoked by fimbria stimulation and when evoked, these "driven" cells were typically coincident with the "field" deflections in that unit discharges were evoked with variable latency (typically $<1-2 \mathrm{msec}$ variance) with the peak of these negative deflections (see Fig. 2, $A-2, B$ ). Cells that could be driven by fimbria stimulation occasionally exhibited some spontaneous activity. However, the rate of spontaneous activity for this type of driven cell was very low $(<1 \mathrm{~Hz})$. Collision tests were not conducted because these driven cells were largely quiescent. However, these cells did not exhibit all or nothing responsiveness to afferent stimulation, demonstrated 1-2 msec variations in latency, and did not exhibit following to highfrequency stimulation. Thus, it is likely that these cells represent NAS cell bodies that were orthodromically activated by hippocampal afferent fiber terminals.

The effects of fimbria stimulation on NAS spontaneous activity also produced a variety of responses (Fig. 1C, Table 1 ). Most of NAS cells were excited (68\%) but other spontaneously active units were inhibited (23\%). Still other units showed complex responses to stimulation (i.e., initial excitation followed by prolonged inhibition), while other cells were unaffected. The cellular response to stimulation was not a function of either cell discharge rate or region. Table 1 summarizes the various NAS cell types encountered and the effects of fimbria stimulation.
Effect of VTA morphine microinfusion on spontaneously active NAS neurons

Previous work has shown that systemically administered opiates can exert a variety of effects on spontaneously active NAS units (Hakan and Henriksen, 1987). Part of this heterogeneous response may have been mediated by opiates acting on DA-ergic cell bodies projecting from the VTA. To test this hypothesis a total of 30 spontaneously active NAS neurons were tested for their response to intra-VTA morphine microinfusion. NAS, fimbria, and VTA sites were histologically verified for 25 of the spontaneous units recorded. Intra-VTA injections of Pontamine sky blue $(1.0 \mu \mathrm{l})$ were restricted to $1.0-$ to $1.5-\mathrm{mm}$-diameter spheres. Fourteen of $25(56 \%)$ cells were depressed $[F(2,8)=$ $13.7, p<0.01], 9(36 \%)$ were unaffected, and $2(8 \%)$ were found to be excited by VTA morphine microinfusions $(F(2,1)=33.1$, $p<0.03$ ). In all cases, opiate cffccts occurred at an average of 6 min postinfusion. Reversal of the effects of VTA morphine microinfusions on NAS neuronal activity was accomplished for all but 3 cells. These 3 cells were lost before reversal was observed. Naloxone $(4.0 \mathrm{mg} / \mathrm{kg}$, s.c.) reversed the inhibitory effects of VTA morphine in $9 / 9$ cells tested. This reversal was also observed to occur at an average 6-7 min after injection. Following VTA morphine microinfusion-induced inhibitions of NAS neuronal activity alpha-flupenthixol (s.c.) elicited reversal 


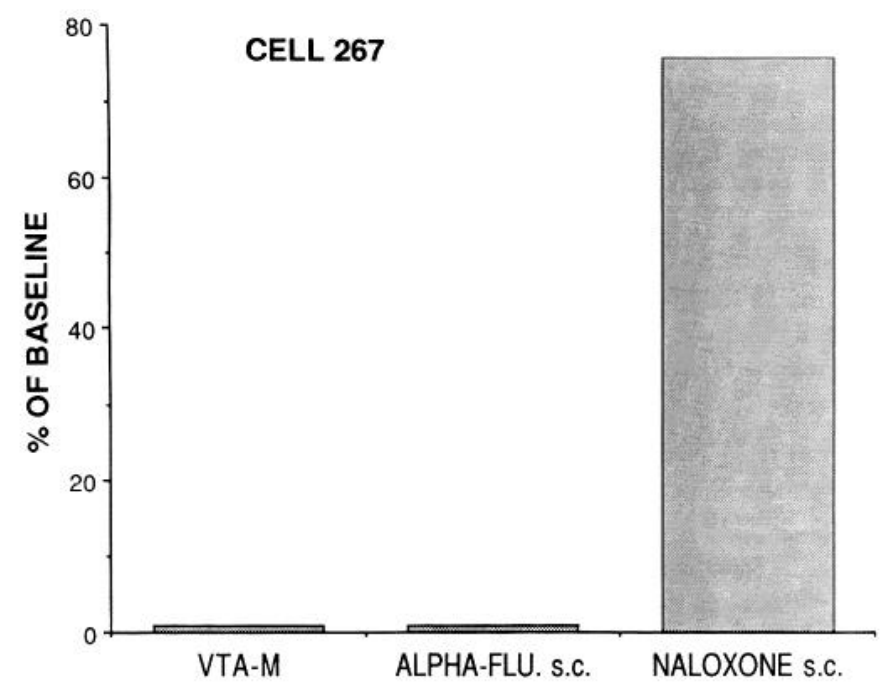

Figure 3. The DA-independent inhibitory effects of VTA morphine microinfusions on fimbria-driven NAS single units. The histogram above shows the consecutive effects of VTA-morphine microinfusion (VTA$M$ ), alpha-flupenthixol (s.c.), and naloxone (s.c.) on a fimbria-driven NAS single unit. Displayed as a function of baseline occurrences counted at near half-maximal stimulation current, VTA-M totally inhibited the driven response of this cell. This inhibition was observed at $\approx 10 \mathrm{~min}$ postinfusion. In contrast to the effects observed for spontaneously active NAS units (see Fig. 3), alpha-flupenthixol (s.c.) was ineffective at reversing this inhibition for driven cells. However, naloxone (s.c., administered at $\approx 40$ min after alpha-flupenthixol) did reverse this VTA-M effect.

in 5/5 spontaneously active cells tested (see Fig. 2, Table 2). This reversal also typically occurred within $10 \mathrm{~min}$ after alphaflupenthixol $[F(2,4)=24.4, p<0.039]$. In some cases, cells that were found to be unaffected by VTA morphine were subse-

\begin{tabular}{|c|c|c|c|}
\hline & $\begin{array}{l}\text { ALPHA-FLU. } \\
\text { S.C. }\end{array}$ & $\begin{array}{l}\text { NALOXONE } \\
\text { S.C. }\end{array}$ & $\begin{array}{l}\text { HEROIN } \\
\text { S.C. }\end{array}$ \\
\hline $\begin{array}{l}\text { DRIVEN } \\
\text { CELLS }\end{array}$ & $0 / 6$ & $10 / 11$ & $7 / 8$ \\
\hline $\begin{array}{l}\text { SPONTANEOUSLY } \\
\text { ACTIVE CELLS }\end{array}$ & $5 / 5$ & $11 / 11$ & $0 / 0$ \\
\hline
\end{tabular}

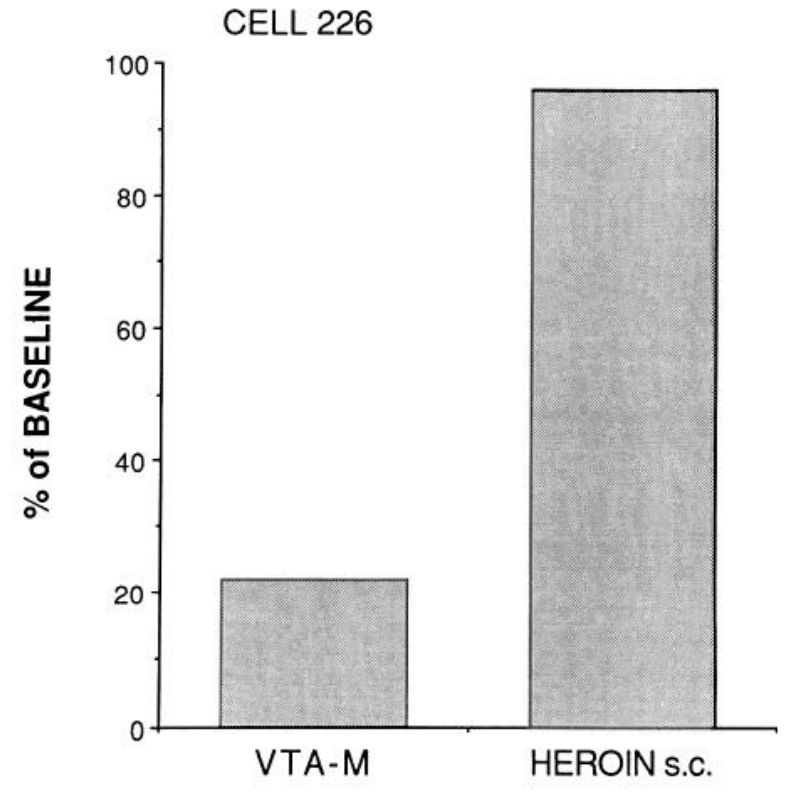

Figure 4. Systemically administered heroin was capable of reversing the inhibition by VTA-morphine infusions $(V T A-M)$ of fimbria-driven NAS single units. This phenomenon is represented by the data from cell 226 above, which is graphed as a function of baseline occurrences counted at near half-maximal stimulation current.

quently tested for response to heroin (s.c.). In $5 / 6$ cases, these cells were also unaffected by heroin, while in 1 case heroin (s.c.) subsequently produced an inhibition that was then reversed with naloxone (s.c.). VTA saline microinfusions had no effects on NAS units $(n=3)$, and in cases where VTA cannula placements were imprecise (i.e., $>1 \mathrm{~mm}$ anterior, posterior, or lateral to the VTA proper, $n=2$ ), morphine microinfusions had no significant effect on NAS activity. In cases where single units of brain regions neighboring the NAS were inadvertently tested ( $n$ $=5$ ), VTA morphine had no effect.

\section{Effect of VTA morphine on driven cells}

NAS silent cells driven by fimbria stimulation (as described above) are unaffected by systemically administered opiates at a full range of stimulation intensities (Hakan and Henriksen, 1987). In this sense, these neurons may represent a special category of NAS cells and were treated as such in the present investigation. Twenty-eight fimbria driven cells were tested for their response to VTA morphine and verified by histology to reside within the NAS region. VTA-morphine microinfusions inhibited 22/28 $(78 \%)$ of the driven cells tested, while $6 / 28(21 \%)$ were unaffected. None of the driven cells tested were excited. The subsequent administration of naloxone (s.c.) reversed the inhibitory effects of VTA morphine in $11 / 12$ cells tested $[F(2,11)=37.0$, $p<0.001$; one cell was lost prior to reversal]. Alpha-flupenthixol (s.c.) was found to be ineffective at reversing these inhibitory effects $(0 / 6)$, though the cells were monitored for $40-60$ min before further attempt was made to reverse the inhibition with naloxone (s.c.). Moreover, though the morphine-induced inhibitions were not reversed with alpha-flupenthixol (s.c.), they were subsequently reversed with naloxine (or heroin; see text below and see Fig. 3 and Table 2). Because fimbria-driven cells are resistant to the effects of systemically applied heroin (Hakan and Henriksen, 1987), it was surprising that these cells were

VTA morphine microinfusions typically inhibited both spontaneously active and fimbria-driven "quiet" cells in the NAS. Reversal of these inhibitions was con sistently observed for both cell types following the administration of naloxone (s.c.). However, alpha-flupenthixol, a DA receptor antagonist, reversed these ef fects only for spontaneously active NAS cells. In some cases, the inhibitory effects of VTA morphine microinfusions on driven cells was subsequently challenged with systemically administered heroin (see text for explanation). Heroin (s.c.) was a potent antagonist of these inhibitions. The first number in each category represents the number of successful reversals observed following alpha-flupenthixo (s.c.), naloxone (s.c.), or heroin (s.c.; see text). The second number represents the total number of attempted reversals. 
CELL 332

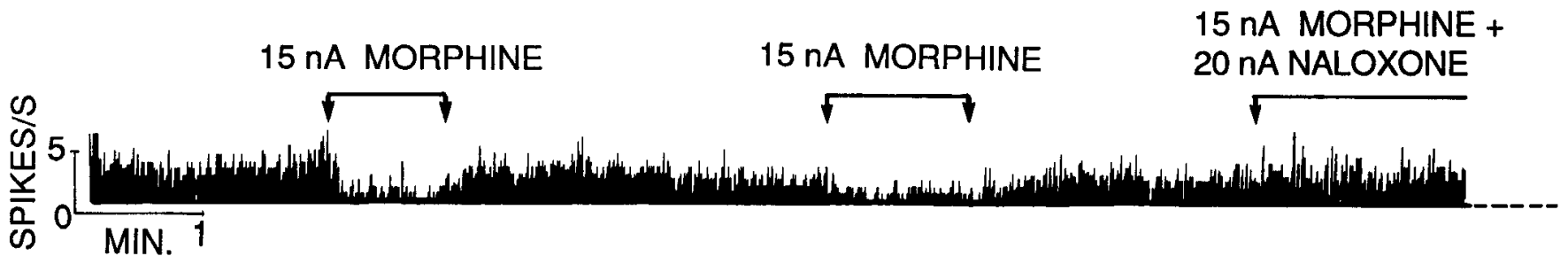

Figure 5. Iontophoretically applied morphine produced inhibitory effects on spontaneously active NAS single units (15/17). The ratemeter record above shows this inhibitory effect on cell 332 and the antagonism of this inhibition by the simultaneous ejection of naloxone. In contrast, iontophoretically applied morphine had no effect on fimbria-driven NAS single units.

inhibited by VTA-morphine. Since systemic heroin may have actions at multiple brain sites, it is possible that actions of heroin on other NAS afferents might counteract these VTA-mediated NAS effects. To test this hypothesis systemic heroin was administered in 8 cases to counter the inhibitory effects of VTA morphine on driven cells. Figure 4 shows an example of a driven cell in which systemic heroin was found to counter the VTAmorphine-induced inhibition. Systemic heroin-induced antagonism of this inhibitory effect was observed in $9 / 10$ cases tested $[F(2,9)=15.5, p<0.0005]$.

\section{Effects of iontophoretically applied morphine on NAS single units}

We have recorded from 30 spontaneously active NAS cells with multibarrel micropipettes. Although this number is not sufficient for a full comparison with the previously described cell population recorded with single-barrel electrodes (Hakan and Henriksen, 1987), the characteristics of these cells appeared to reflect those of this larger sample. For example, driven cells ( $n$ $=13)$ and slow cells $(n=12)$ were encountered equally as described for the larger population. A significant number of fast cells were also encountered but with a lower frequency than that found for single-barrel recording. We found $15 / 17$ spontaneously active NAS units to be inhibited by electrophoretically released morphine $(5-30 \mathrm{nA})$, while 2 were unaffected. These inhibitions typically occurred within 1-2 min for all cells tested. In all cases tested, morphine effects were blocked by the simultaneous ejection of naloxone ( $15 \mathrm{nA}, n=3)$. Figure 5 shows these iontophoretic effects in a representative NAS cell. Iontophoretically applied morphine had no effect on the evoked excitability of fimbria-driven NAS units $(n=13)$.

\section{Discussion}

The NAS appears to be critical for opiate self-administration in rats (Goeders et al., 1984; Vaccarino et al., 1985; Corrigal and Vaccarino, 1988; Koob and Goeders, 1989). However, the relative roles of intrinsic and/or specific afferent neurochemical systems mediating this NAS-dependent behavior remains unresolved. Some investigators have attributed primary importance to VTA-DA input to the NAS (see Wise, 1987), while others have offered evidence suggesting that postsynaptic mechanisms within the NAS proper are primary for this behavior (see Swerdlow et al., 1986). The present electrophysiological study was designed to further investigate the potential neurochemical and cellular basis of opiate self-administration by assessing the role of VTA-DA afferent projections in the effects of systemic opiates on NAS neuronal activity.
Overall, spontaneously active NAS single units were inhibited (56\%) by microinfusions of morphine into the VTA. This inhibition was consistently reversed by subsequent administration (s.c.) of either naloxone or alpha-flupenthixol. Reversal of the inhibitory effect of VTA morphine microinfusions by systemically administered alpha-flupenthixol suggests dopaminergic mediation. Fimbria-driven silent cells encountered in the NAS were also inhibited by microinfusions of morphine to the VTA. This inhibition was reversed with systemically administered naloxone but not by alpha-flupenthixol, suggesting a nondopaminergic mechanism. Further, systemically administered heroin was found to reverse the inhibitory effects of VTA opiate microinfusions on fimbria-driven activity. This finding, along with other evidence (see below), suggests that systemically administered opiates are likely to affect NAS neuronal activity by acting on other, as yct unidentified brain structures projecting to the NAS that contain opioid receptors. In addition, results from our studies of iontophoretically applied morphine onto individual NAS neurons indicate that opiates also can act directly on opioid receptors within the NAS to inhibit spontaneously active cells (Fig. 5). Therefore, these results provide evidence that systemic opiate effects on NAS neurons involve both DA afferents from the VTA, nondopaminergic input from the VTA, other NAS-afferent systems, as well as opiate effects mediated within the NAS proper. Although the relative contributions of these sites of opiate action for opiate reward remain to be elucidated in the unrestrained, opiate self-administration preparation, the present results suggest that systemically selfadministered opiate actions on NAS neural activity will involve an array of direct and indirect actions. Thus, important aspects of opiate reward will probably be best understood by understanding the overall changes in circuit activity converging in the NAS following opiate administration.

A more detailed analysis of our electrophysiological results provides a more complex picture of the NAS than has been previously described. In agreement with past work from our laboratory (Hakan and Henriksen, 1987), the NAS was observed to be a region of great electrophysiological heterogeneity. Our recordings from over 300 isolated single units in the NAS of halothane-anesthetized rats have indicated that fast, slow, and fimbria-driven unit activity appear equally distributed throughout the NAS. These observations partially contrast with reports that have described the NAS as a region of predominant inactivity (Yim and Mogenson, 1982; White and Wang, 1984; Yang and Mogenson, 1984). Although slow or inactive cells were regularly encountered, many cells showed considerable spontaneous activity (67\%). We also observed diversity in NAS unit 
responses to fimbria stimulation. In contrast to studies indicating regional specificity of NAS responses to fimbria stimulation (Yang and Mogenson, 1984), the data presented here show that inhibition, excitation, or lack of response to fimbria stimulation were observed without obvious relationship to the baseline rates of neuronal activity nor the region of recording. Moreover, despite earlier anatomical and electrophysiological evidence suggesting hippocampal terminations predominantly in the caudal, dorsomedial, and lateral NAS (see Yang and Mogenson, 1984; De France et al., 1985), fimbria-driven discharges, thought to represent monosynaptic responses of NAS medium-sized spiny neurons and large aspiny neurons (De France et al., 1985), were encountered throughout the NAS in our study. This electrophysiological observation is consistent with a more recent anatomical report of Groenwegen et al. (1987).

The inhibitory effect of iontophoretically applied morphine we report is in accord with an earlier brief report in which homocysteic acid-stimulated NAS neurons were uniformly inhibited by iontophoretically applied opioids (McCarthy et al., 1977). However, the lack of effect of phoretically applied morphine on fimbria-driven cells observed here, as well as the diversity in response of NAS neurons to systemic opiate administration (Hakan and Henriksen, 1987), contrasts with this earlier report. In addition, as only $50 \%$ of the "fast" neurons we recorded in the NAS were affected by VTA morphine microinfusions, this also contrasts with previously reported uniform inhibitions of fast-firing spontaneously active NAS neurons by VTA conditioning stimulation (or iontophoretic application of DA) (Yang and Mogenson, 1984).

It is possible that some of the reported differences in NAS cell activity and NAS opiate neuropharmacology result as a function of anesthetic used. The majority of the early studies of NAS cellular activity used either urethane or chloral hydrate anesthesia, while low-level halothane anesthesia was used in the present investigations. Anesthetic-dependent drug effects have previously been reported in other brain regions but not the NAS (Chapin et al., 1981; Rogers et al., 1986).

\section{Avenues of opiate influence on NAS unit activity \\ The VTA}

It is known that opiates have excitatory effects on VTA neurons (Glysing and Wang, 1983; Mathews and German, 1984), and VTA DA-derived modulation of NAS neuronal activity is consistent with studies showing that iontophoretically applied DA as well as VTA stimulation can inhibit NAS unit activity induced by either homocysteic acid (e.g., Woodruff et al., 1976), glutamate (e.g., Yim and Mogenson, 1982), or CCK (White and Wang, 1984). In the present study, microinfusions of morphine into the VTA produced inhibitory (presumably dopaminergic) effects on $56 \%(14 / 25)$ of the spontaneously active NAS cells tested. Likewise, since DA agonists or VTA stimulation inhibit the excitatory NAS responses to amygdala (Yim and Mogenson, 1982), hippocampal (Yang and Mogenson, 1984), or parafascicular stimulation (Akaike et al., 1981), the inhibition of fimbria-driven silent cells $(76 \% ; 19 / 25)$ is consistent with a DAmediated action. However, unlike the effects observed for spontaneously active NAS neurons, the VTA morphine-induced inhibition of fimbria-driven silent cells was not reversed with alpha-flupenthixol, suggesting a nondopaminergic mechanism. Collectively, these data indicate that VTA neurons can effect NAS cellular activity through both dopaminergic and nondopaminergic mechanisms. Other studies have demonstrated that the VTA sends both DA and non-DA fibers to the NAS (Maeda and Mogenson, 1980; Thierry et al., 1980; Yim and Mogenson, 1980). Evidence for the colocalization of both CCK and neurotensin with VTA-DA also exist (Hökfelt et al., 1980; White and Wang, 1984) and have been shown to exhibit differential behavioral relevance (Weiss et al., 1988). Thus, these other substances may be likely candidate neurochemical substrates for the DA-independent effects of VTA-morphine microinfusions on fimbria-driven NAS responses. Finally, since a total of $30 \%(15 / 50)$ of the NAS cells we tested were insensitive to verified VTA opiate microinfusions, a significant number of NAS neurons may be independent of any VTA influence altogether.

The role of DA in the VTA-NAS fiber system is unquestionably important and implied by the present data to have a significant role in the effects of systemically applied opiates on NAS activity. However, it is also likely that nondopaminergic mechanisms have a significant role in the response of NAS cells to opiates as well. In this regard, it should be pointed out that although VTA stimulation does have inhibitory effects on NAS activity, most NAS cells are unaffected by single-pulse VTA stimulation (Yim and Mogenson, 1982; Le Douarin et al., 1986). Even when VTA stimulus trains are employed to enhance these inhibitory effects, many NAS neurons ( $>20 \%$ ) remain unaffected (Yim and Mogenson, 1982). Moreover, the tremendous extent of reciprocal fiber connections between the NAS and its afferent nuclei (e.g., Chronister et al., 1981; Phillipson and Griffiths, 1985), as well as the existence of opioid binding sites within many of these afferent structures (Mansour et al., 1988) suggests numerous mechanisms of opiate influence on the NAS.

Systemically administered drugs typically excrt dircct receptor-specific effects at multiple, but distinct, brain sites to affect behavior. Because fimbria-driven NAS activity was predominantly inhibited $(78 \%)$ by VTA opiate microinfusions but uniformly unaffected by systemically administered opiate drugs (Hakan and Henriksen, 1987), systemic opiates must also have had effects on brain regions that counteracted the action of opiate effects elicited from the VTA alone. This idea is supported by the fact that systemically administered heroin reversed the VTA opiate-induced inhibition of fimbria-driven NAS activity. Although the mechanism of this process is not clear, the present data suggest that systemic opiate effects on other NAS afferent systems may be involved since microiontophoresis of morphine onto fimbria-driven cells was without effect. Inhibitory effects on NAS neurons by other afferent systems have, in fact, been observed. For example, excitation of NAS units by hippocampal stimulation can be inhibited by preconditioning stimulation of the locus coeruleus (Unemoto et al., 1985), a structure known to contain opioid receptors (see Mansour et al., 1988).

Iontophoretically applied opiates did inhibit spontaneous NAS activity in the present study, indicating that systemically administered opiates may have significant direct actions on NAS neurons in addition to indirect actions mediated by NAS afferent systems. A direct effect of opiates in the NAS is also consistent with the self-administration of opiates in rats by microinfusion directly into the NAS. Studies demonstrating that the selfadministration of systemically applied opiate drugs in rats can be blocked by intra-NAS microinfusion of the stable opiate antagonist, methylnaloxonium (Vaccarino et al., 1985; Corrigal and Vaccarino, 1988) also suggest that opiates may have direct actions in the NAS. Direct NAS opiate effects are probably independent of DA influences since 6-hydroxydopamine-in- 
duced DA denervation of the NAS does not disrupt the intravenous self-administration of opiates in rats (see Koob and Goeders, 1989). Indeed, preliminary investigations in our laboratory have found opiate-induced inhibitions of NAS spontaneously active units in rats pretreated with 6-hydroxydopamine.

\section{Conclusions}

The present data in conjunction with earlier work (Hakan and Henriksen, 1987) demonstrate that the effects of systemically administered opiates on NAS neurons must occur through both the VTA-DA projection to the NAS, as well as directly within the NAS. In addition, a significant non-DA VTA influence on NAS neuronal activity can be elicited by morphine microinfusions. It is also likely that opioids affect the NAS by acting on NAS afferent systems in addition to the VTA. Evidence provided here suggest that systemic opiate effects on NAS afferents may act in a summatory fashion so that actions on one afferent system may be altered by effects on other NAS afferent systems. Consequently, it may prove valuable to further examine this model of how opioid drugs (or other drugs of abuse or natural reinforcers) affect the NAS through these multiple afferent systems, as well as how the effective changes in NAS neuronal activity reciprocally influence NAS afferent and efferent nuclei.

\section{References}

Akaike, A., M. Sasa, and S. Takaori (1981) Inhibition from ventral tegmental area of nucleus accumbens neurons in the rat. Brain Res. 225: 189-194.

Amalric, M., and G. F. Koob (1985) Low doses of methylnaloxonium in the nucleus accumbens antagonize hyperactivity induced by heroin in the rat. Pharmacol. Biochem. Behav. 23: 411-415.

Beninger, R. J. (1983) The role of dopamine in locomotor activity and learning. Brain Res. Rev. 6: 173-196.

Bozarth, M. A., and R. A. Wise (1981) Intracranial self-administration of morphine into the ventral tegmental area in rats. Life Sci. 28: 551555.

Chapin, J. K., B. D. Waterhouse, and D. J. Woodward (1981) Differences in cutaneous sensory response properties of single somatosensory cortical neurons in awake and halothane anesthetized rats. Brain Res. Bull. 6: 63-70.

Chronister, R. B., and J. F. De France (1981) Nucleus accumbens in historical perspective. In The Neurobiology of the Nucleus Accumbens, R. B. Chronister and J. F. De France, eds., pp. 1-6, Haer Inst. Press, Brunswick, ME.

Chronister, R. B., R. W. Sikes, T. W. Trow, and J. F. De France (1981) The organization of the nucleus accumbens. In The Neurobiology of the Nucleus Accumbens, R. B. Chronister and J. F. De France, eds., pp. 97-146, Haer Inst. Press, Brunswick, ME.

Corrigal, W. A., and F. J. Vaccarino (1988) Antagonist treatment in nucleus accumbens or periaqueductal grey affects heroin self-administration. Pharmacol. Biochem. Behav. 30: 443-450.

De France, J. F., and H. Yoshihara (1975) Fimbria input to the nucleus accumbens septi. Brain Res. 90: 447-462.

De France, J. F., J. F. Marchand, R. W. Sikes, R. B. Chronister, and J. I. Hubbard (1985) Characterization of timbria input to nucleus accumbens. J. Neurophysiol. 54: 1553-1567.

Di Chiara, G., and A. Imperato (1988) Opposite effects of mu and kappa opiate agonists on dopamine release in the nucleus accumbens and in the dorsal caudate of freely moving rats. J. Pharmacol. Exp. Ther. 244: 1067

Glysing, K., and R. Y. Wang (1983) Morphine-induced activation of A10 dopamine neurons in the rat. Brain Res. 277: 119-127.

Goeders, N. E., J. D. Lane, and J. E. Smith (1984) Intracranial selfadministration of methionine enkephalin into the nucleus accumbens. Pharmacol. Biochem. Behav. 20: 451-455.

Groenwegen, H. J., N. E. H. M. Becker, and A. H. M. Lohman (1980) Subcortical afferents of the nucleus accumbens septi in the cat, studied with retrograde axonal transport of horseradish peroxidase and besbenzimid. Neuroscience 5: 1903-1916.

Groenwegen, H. J., E. Vermeulen-Van Der Zee, A. Te Kortschot, and M. P. Witter (1987) Organization of the projections from the subiculum to the ventral striatum in the rat. A study using anterograde transport of phaseolus vulgaris leucoagglutinin. Neuroscience 23: 103120.

Hakan, R. L., and S. J. Henriksen (1987) Systemic opiate administration has heterogeneous effects on activity recorded from nucleus neurons in vivo. Neurosci. Lett. 83: 307-312.

Heimer, L., and R. D. Wilson (1975) The subcortical projections of the allocortex: Similarities in the neural associations of the hippocampus, the piriform cortex, and the neocortex. In Golgi Centennial Symposium Proceedings, M. Santini, ed., pp. 177-193, Raven, New York.

Herkenham, M., S. Moon Edley, and J. Stuart (1984) Cell clusters in the nucleus accumbens of the rat, and the mosaic relationship of opiate receptors, acetylcholinesterase and subcortical afferent terminations. Neuroscience 11: 561-593.

Hökfelt, T., J. F. Rehfeld, L. Skirboll, B. Ivemark, M. Goldstein, and K. Marley (1980) Evidence for coexistence of dopamine and CCK in mesolimbic neurons. Nature 285: 476-478.

$\mathrm{Hu}, \mathrm{X}$. T., and R. Y. Wang (1984) Comparison of morphine-induced effects on dopamine and non-dopamine neurons in the rat ventral tegmental area. Soc. Neurosci. Abstr. 10:23.5.

Jones, D. L., and G. J. Mogenson (1980) Nucleus accumbens to globus pallidus GABA projections: Electrophysiological and iontophoretic investigations. Brain Res. 188: 93-105.

Kalivas, P. W., E. Widerlov, D. Stanley, G. Breese, and A. J. Prange, Jr. (1983) Enkephalin action on the mesolimbic dopamine system: A dopamine-dependent and a dopamine-independent increase in locomotor activity. J. Pharmacol. Exp. Ther. 227: 229-237.

Kelley, A. E., and V. B. Domesick (1982) The distribution of the projection from the hippocampal formation to the nucleus accumbens in the rat: An anterograde- and retrograde-horseradish peroxidase study. Neuroscience 7: 2321-2335.

Kelley, A. E., and L. Stinus (1984) The distribution of the projection from the parataenial nucleus of the thalamus to the nucleus accumbens in the rat: An autoradiographic study. Exp. Brain Res. 54: 499512.

Kelly, A. E., L. Stinus, and S. D. Iversen (1980) Interactions between D-Ala-Met-enkephalin, A10 dopaminergic neurons, and spontaneous behavior in the rat. Behav. Brain Res. 1: 3-24.

Kelly, P. H., P. W. Seviour, and S. D. Iversen (1975) Amphetamine and apomorphine responses in the rat following 6-OHDA lesions of the nucleus accumbens septi and corpus striatum. Brain Res. 94: 507522.

Koob, G. F., and N. E. Goeders (1989) Neuroanatomical substrates of drug self-administration. In The Neuropharmacological Basis of Reward, J. M. Liebman and S. J. Cooper, eds., Oxford U. P., New York.

Ksir, C. K., and E. J. Kline (1987) 6-OHDA lesions of the nucleus accumbens block the stimulant effects of nicotine in rats. Soc. Neurosci. Abstr. 13: 126.1.

Le Douarin, C., J. Penit, J. Glowinski, and A. M. Thierry (1986) Effects of ventromedial mesencephalic tegmentum (VMT) stimulation on the spontancous activity of nucleus accumbens ncurons: Influence of the dopamine system. Brain Res. 363: 290-298.

Maeda, H., and G. J. Mogenson (1980) An electrophysiological study of the inputs to neurons of the ventral tegmental area and from the nucleus accumbens and medial preoptic-anterior hypothalamic areas. Brain Res. 197: 365-377.

Mansour, A., H. Kachaturian, M. E. Lewis, H. Akil, and S. J. Watson (1988) Anatomy of CNS opioid receptors. TINS 11: 308-314.

Mathews, R. T., and D. C. German (1984) Electrophysiological evidence for excitation of rat ventral tegmental area dopamine neurons by dopamine. Neuroscience 11: 617-625.

McCarthy, P. S., R. J. Walker, and G. N. Woodruff (1977) Depressant action of enkephalins on neurons in the nucleus accumbens. J. Physiol. (Lond.) 267: 40.

Mogenson, G. J. (1987) Limbic-motor integration. Prog. Physiol. Psychol. 12: 117-170.

Nauta, W. J. H., G. P. Smith, R. L. M. Faull, and V. B. Domesick (1978) Efferent connections and nigral afferents of the nucleus accumbens septi in the rat. Neuroscience 3: 385-401. 
Newman, R., and S. S. Winans (1980) An experimental study of the ventral striatum of the golden hamster. I. Neuronal connections of the nucleus accumbens. J. Comp. Neurol. 191: 167-192.

Nowycky, M. C., J. R. Walters, and R. H. Roth (1978) Dopaminergic neurons: Effect of acute and chronic morphine administration on single cell activity and transmitter metabolism. J. Neural Trans. 42: 99-1 16.

Paxinos, G., and C. Watson (1982) The Rat Brain in Stereotaxic Coordinates, Academic, New York.

Pettit, H. O., A. Ettenberg, F. E. Bloom, and G. F. Koob (1984) Destruction of dopamine in the nucleus accumbens selectively attenuates cocaine but not heroin self-administration in rats. Psychopharmacology 84: 167-173.

Phillipson, O. T., and A. C. Griffiths (1985) The topographic order of inputs to nucleus accumbens in the rat. Neuroscience 16:275-296.

Pijenburg, A. J. J., and J. M. Van Rossum (1973) Stimulation of locomotor activity following injection of dopamine into the nucleus accumbens. J. Pharm. Pharmacol. 25: 1003-1005.

Powell, E. W., and R. B. Leman (1976) Connections of the nucleus accumbens. Brain Res. 105: 389-403.

Rogers, J., S. G. Madamba, D. A. Staunton, and G. R. Siggins (1986) Ethanol increases single-unit activity in the inferior olivary nucleus. Brain Res. 385: 253-262.

Stinus, L., G. F. Koob, N. Ling, F. E. Bloom, and M. LeMoal (1980) Locomotor activation induced by infusion of endorphins into the ventral tegmental area. Proc. Natl. Acad. Sci. USA 77: 2323-2327.

Swanson, L. W., and W. M. Cowan (1975) A note on the connections and development of the nucleus accumbens. Brain Res. 92: 324-330.

Swerdlow, N. R., F. J. Vaccarino, M. Amalric, and G. F. Koob (1986) The neural substrates for the motor-activating properties of psychostimulant: A review of recent findings. Pharmacol. Biochem. Behav. $25:$ 233-248.

Thierry, A. M., J. M. Deniau, D. Herve, and G. Chevalier (1980) Electrophysiological evidence for non-dopaminergic mesocortical and mesolimbic neurons in rat. Brain Res. 201: 210-214.

Troiano, R., and A. Siegel (1978) Efferent connections of the basal forebrain in the cat: The nucleus accumbens. Exp. Neurol. 61: 185 197.

Unemoto, H., M. Sasa, and S. Takaori (1985) Inhibition from locus coeruleus of nucleus accumbens neurons activated by hippocampal stimulation. Brain Res. 338: 376-379.
Unterwald, E. M., G. F. Koob, and R. S. Zukin (1986) Characterization and neuroanatomical localization of multiple opioid receptors in rat brain following selective nucleus accumbens lesions. Soc. Neurosci. Abstr. 12: 48.11.

Vaccarino, F. J., F. E. Bloom, and G. F. Koob (1985) Blockade of nucleus accumbens opiate receptors attenuates the intravenous heroin reward in the rat. Psychopharmacology 86: 37-42.

Vaccarino, F. J., M. Amalric, N. R. Swerdlow, and G. F. Koob (1986) Blockade of amphetaminc but not opiate induced locomotion following antagonism of dopamine function in the rat. Pharmacol. Biochem. Behav. 24: 61-65.

Wamsley, J. K., W. S. Young, and M. J. Kuhar (1980) Immunohistochemical localization of enkephalin in rat forebrain. Brain Res. 190: 153-174.

Weiss, F., D. J. Tanzer, and A. Ettenberg (1988) Opposite actions of CCK-8 on amphetamine-induced hyperlocomotion and stereotypy following intracerebroventricular and intra-accumbens injections in rats. Pharmacol. Biochem. Behav. 30: 309-317.

White, F. J., and R. Y. Wang (1984) Interactions of cholecystekinin octapeptide and dopamine on nucleus accumbens neurons. Brain Res. 300: 161-166.

Williams, D. J., A. R. Crossman, and P. Slater (1977) The efferent projections of the nucleus accumbens in the rat, Brain Res. 130:217227.

Wise, R. A. (1984) Neural mechanisms of the reinforcing actions of cocaine. Natl. Inst. Drug Abuse Res. Monogr. Ser. 50: 15-33.

Wise, R. A. (1987) The role of reward pathways in the development of drug dependence. Pharmacol. Ther. 35: 227-263.

Woodruff, G. N., P. S. McCarthy, and R. J. Walker (1976) Studies on the pharmacology of neurons in the nucleus accumbens of the rat. Brain Res. 115: 233-242.

Yang, C. R., and G.J. Mogenson (1984) Electrophysiological responses of neurons in the nucleus accumbens to hippocampal stimulation and the attenuation of the excitatory responses by the mesolimbic dopaminergic system. Brain Res. 324: 69-84.

Yim, C. Y., and G. J. Mogenson (1980) Electrophysiological studies of neurons in the ventral tegmental arca of Tsai. Brain Res. 181: 301313.

Yim, C., and G. J. Mogenson (1982) Response of nucleus accumbens neurons to amygdala stimulation and its modification by dopamine. Brain Res. 239: 401-415. 